\title{
Preparation and Characterization of Nanocrystalline PbS Thin Films Produced by Chemical Bath Deposition
}

\author{
F. GÖDE ${ }^{a, *}$, F. YAVUZ ${ }^{a}$ AND İ.A. KARiPER ${ }^{b}$ \\ ${ }^{a}$ Mehmet Akif Ersoy University, Physics Department, Burdur, Turkey \\ ${ }^{b}$ Erciyes University, Primary Education Department, Kayseri, Turkey
}

\begin{abstract}
Lead sulfide thin films are deposited on glass substrates at room temperature for $2 \mathrm{~h}$ by chemical bath deposition. The structure, surface morphology, optical and electrical properties of the thin films are characterized by X-ray diffraction, scanning electron microscopy, atomic force microscopy, optical absorption spectroscopy and the Hall effect measurements. The obtained films show the formation of well crystallized PbS with a cubic rock salt structure and with the preferential orientation (111) plane. The lattice parameter and crystallite size of the films are found as $a=600 \AA$ and $62 \mathrm{~nm}$ from the X-ray reflectivity data from the atomic force microscopy image, respectively. The band gap width of the films is determined as $2.84 \mathrm{eV}$. The optical parameters of the films such as refractive index, extinction coefficient, real and imaginary parts of dielectric constant are evaluated. Moreover, from the Hall measurements, electrical resistivity, conductivity carrier mobility, and carrier concentration of the films are determined as $3.722 \Omega \mathrm{m}, 0.268 \Omega^{-1} \mathrm{~m}^{-1}, 8.486 \times 10^{-1} \mathrm{~m}^{2} \mathrm{~V}^{-1} \mathrm{~s}^{-1}$, and $1.976 \times 10^{18} \mathrm{~m}^{-3}$, respectively.
\end{abstract}

DOI: 10.12693/APhysPolA.128.B-215

PACS: 68.37.Ps, 68.55.-a, 78.20.--e, 73.61.Ga

\section{Introduction}

In recent years, there has been increasing interest in IV-VI semiconductor materials for their application in optoelectronic and photovoltaic industries. One of the most promising alternative materials is lead sulfide $(\mathrm{PbS})$ thin films owing to their optical and electrical properties being different from those of their bulk counterparts, due to the quantum confinement effect [1]. Their band gap width can be varied from the bulk value of $0.41 \mathrm{eV}$ to $2.3 \mathrm{eV}$ by changing the crystallite size [2]. $\mathrm{PbS}$ is used in many semiconductor devices such as transistors [3], IR detectors [4], biosensors [5] and solar cells [6], etc. $\mathrm{PbS}$ thin films can be obtained by several methods such as electrodeposition [7], solvothermal [2], successive ionic layer adsorption and reaction (SILAR) $[8]$ and chemical bath deposition (CBD) [9], etc. Among them, CBD is an economical and simple technique and enables largescale deposition. Moreover, the preparative conditions are easily controlled.

In this work, nanocrystalline $\mathrm{PbS}$ thin films are produced on glass substrates at room temperature for $2 \mathrm{~h}$ by $\mathrm{CBD}$ and their crystalline structure, surface morphology optical and electrical properties are studied. The refractive index, extinction coefficient, real and imaginary parts of dielectric constant are determined from the transmittance and absorbance measurements. Moreover, electrical conductivity, carrier mobility and carrier concentration of the films are obtained by the Hall effects measurements.

*corresponding author; e-mail: ftmgode@gmail.com

\section{Experimental details}

Prior to deposition, the glass substrates $(76 \times 26$ $\times 1 \mathrm{~mm}^{3}$ ) were immersed in boiling water with detergent, and then soaked in chromic acid, cleaned in isopropyl alcohol, rinsed in distilled water and finally dried in air. The deposition mixture was prepared by placing a $2.5 \mathrm{ml}$ $0.5 \mathrm{M}$ of lead acetate $\left[\left(\mathrm{PbCH}_{3} \mathrm{COOH}\right) \cdot 2 \mathrm{H}_{2} \mathrm{O}\right]$ solution in a $50 \mathrm{ml}$ beaker, followed by the addition of $2.5 \mathrm{ml} 2 \mathrm{M}$ of sodium hydroxide $(\mathrm{NaOH}, \mathrm{pH}=12.63), 3 \mathrm{ml} 1 \mathrm{M}$ of thiourea $\left(\mathrm{NH}_{2} \mathrm{CSNH}_{2}\right), 1 \mathrm{ml} 1 \mathrm{M}$ of triethanolamine TEA $\left[\left(\mathrm{HOCH}_{2} \mathrm{CH}_{2}\right)_{3} \mathrm{~N}\right], 0.4 \mathrm{ml} 0.5 \mathrm{M}$ tri-sodium citrate TSC $\left(\mathrm{C}_{6} \mathrm{H}_{5} \mathrm{Na}_{3} \mathrm{O}_{7}\right)$ and then the total volume of the solution was completed to $50 \mathrm{ml}$ by adding deionized water. Triethanolamine and tri-sodium citrate were used as complexing agents. The final $\mathrm{pH}$ of the solution was measured as 9.97. The glass substrate was placed vertically inside the glass beaker. The preparation conditions such as solution concentration, $\mathrm{pH}$ value, deposition time and bath temperature were optimized in order to get nanocrystalline $\mathrm{PbS}$ thin films. The solution color turned into light grey in $30 \mathrm{~min}$. Then its color became deeper with the increase of the reaction time till it changed into dark grey completely. So, it was seen that the obtained films were homogeneous with a bright dark grey color.

The structural characterization of the films are performed by a Rigaku RadB X-ray diffractometer (XRD) system using $\mathrm{Cu} K_{\alpha}$ radiation $(1.54056 \AA)$ in $2 \theta$ ranging from 20 to $40^{\circ}$ at a speed of $3^{\circ} / \mathrm{min}$, with a step size of $0.02^{\circ}$. The operating voltage and the current used for the XRD study are $40 \mathrm{kV}$ and $40 \mathrm{~mA}$, respectively. The morphology of the films is characterized using a scanning electron microscope (SEM) (EVO40-LEO) with magnification of $30,000 \times$, and with an operating voltage of $20 \mathrm{kV}$. The film thickness, roughnes and section analysis of the obtained films are performed using 
a VEECO Multimode 8 model atomic force microscopy (AFM). The optical band gap of the films was evaluated using the absorption data recorded using a Perkin Elmer UV/Vis Lambda 4S spectrophotometer, providing a wavelength range from 290 to $1100 \mathrm{~nm}$ using a non-coated glass as the reference beam. The electrical properties of the $\mathrm{PbS}$ films are studied at room temperature using a Hall effect measurement setup with a Van der Pauw geometry and a magnetic field of $0.54 \mathrm{~T}$.

\section{Results and discussions}

Figure 1a shows the XRD spectrum for the nanocrystalline $\mathrm{PbS}$ thin film. The narrow peak shows good crystallinity of the film. The film exhibits only one intense peak corresponding to the plane (111) of PbS cubic rock salt structure (PDF no. 05-0592). The diffraction peak of cubic $\mathrm{PbS}$ is observed at $2 \theta$ value of angle around $25.68^{\circ}$. The structural data are also in agreement with the reported data by Moreno-García et al. [10].

The lattice constant $(a)$ is calculated using the observed value of $2 \theta=25.68^{\circ}$ for the (111) plane and the $d$ value (inter-planar spacing) for the cubic structure which is given by the following formula:

$$
a=d \sqrt{h^{2}+k^{2}+l^{2}}
$$

where $(h k l)$ are the Miller indices of the plane concerned. The estimated value of lattice constant for the films $(6.00 \AA)$ is very close to the reference data for the bulk $\mathrm{PbS}(5.94 \AA)$.
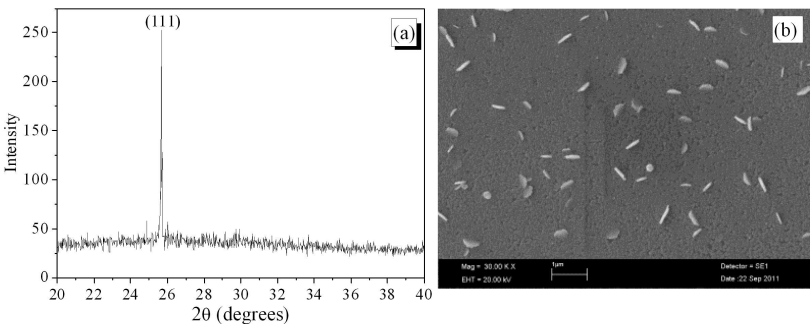

Fig. 1. (a) X-ray diffraction pattern for the nanocrystalline PbS thin film and (b) the SEM micrograph for the nanocrystalline $\mathrm{PbS}$ thin film with magnification of $30,000 \times$.

Figure 1b shows the SEM micrograph of the $\mathrm{PbS}$ film recorded in the backscattered mode. As can be clearly seen in the SEM micrographs, the film surface consists of smooth granular structure with small grains. Some clusters are seen on the film surface, and large particles protrude from the surfaces of the PbS thin film. The formation of these grains on the PbS films surface is also observed in other works $[11,12]$.

AFM images of the PbS thin film are used to study the surface morphology, grain size, roughness, thickness and section analysis of the PbS films. Two-dimensional AFM image shows that the average grain size of the $\mathrm{PbS}$ nanoparticle is around $62 \mathrm{~nm}$ in Fig. 2a. Threedimensional AFM image reveals that the surface of the film is almost smooth with very few mount like structures as shown in Fig. 2b. In Fig. 2c, the surface roughness of the film is measured to be $5.130 \mathrm{~nm}$, which is less than the reported data $(10.81 \mathrm{~nm})$ by Kumar et al. [13]. Figure 2d shows the AFM images for cross-sectional morphology of $\mathrm{PbS}$ thin film. It is seen from the figure that the film thickness is approximately $100 \mathrm{~nm}$.
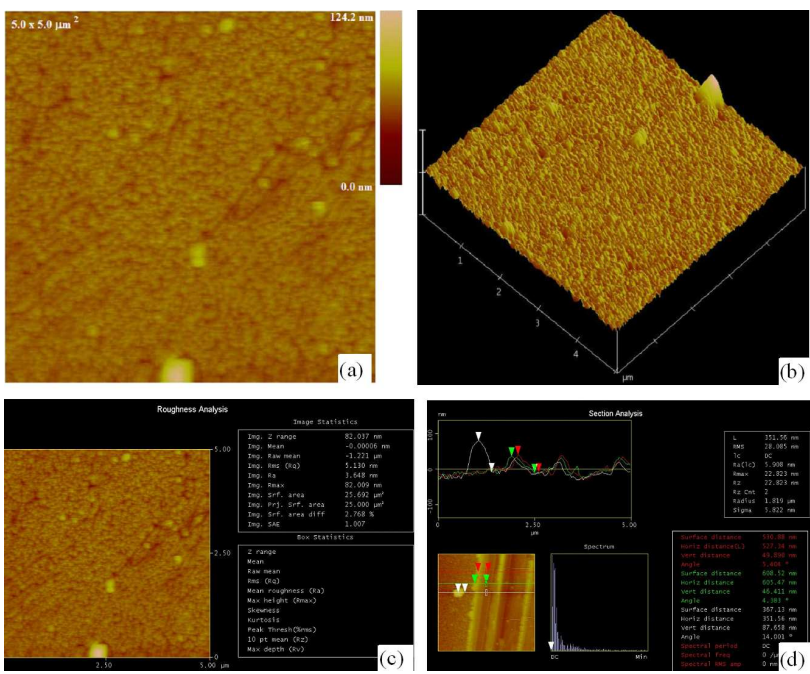

Fig. 2. (a) Two-dimensional AFM image, (b) threedimensional AFM image, (c) average roughness and (d) cross-section analysis for the nanocrystalline PbS thin film.

The UV-Vis transmittance and reflectance spectra for the $\mathrm{PbS}$ film are shown in Fig. 3a. It is seen from this figure that the transparency of the deposited film at $\lambda=550 \mathrm{~nm}$ is $40 \%$ in the visible region and $76 \%$ in the near infrared (NIR) region. The optical absorption coefficient $(\alpha)$ which is found as the order of $10^{3} \mathrm{~cm}^{-1}$ in the wavelength range $290-1100 \mathrm{~nm}$ using the following equation:

$$
T=(1-R)^{2} \exp (\alpha t),
$$

where $T$ is the transmittance, $R$ is the reflectance and $t$ is the film thickness. Absorption coefficient is lower than obtained $\left(10^{4} \mathrm{~cm}^{-1}\right)$ by Abbas et al. [14].
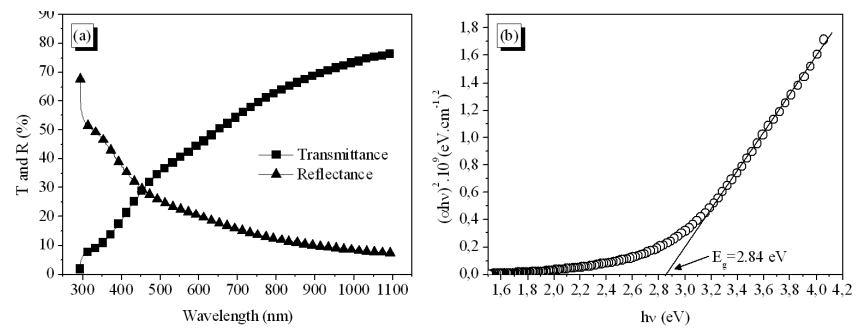

Fig. 3. (a) Optical transmittance and reflectance spectra and (b) plot of $(\alpha h \nu)^{2}$ versus $(h \nu)$ for the nanocrystalline $\mathrm{PbS}$ thin film.

The variation of the optical absorption coefficient with wavelength is analyzed to find out the nature of the 
electronic transition across the optical band gap. The nature of the transition is determined using the relation:

$$
\alpha h \nu=B\left(h \nu-E_{\mathrm{g}}\right)^{n},
$$

where $B$ is a constant, $h$ is the Planck constant, $\nu$ is the frequency of photon and $n$ equals to $\frac{1}{2}$ for direct band gap. Band gap width $\left(E_{\mathrm{g}}\right)$ of $\mathrm{PbS}$ thin films can be obtained by extrapolating the straight line of $(\alpha h \nu)^{2}$ vs. $h \nu$ curve to intercept the horizontal $h \nu$ axis and is shown in Fig. 3b. It can be seen that the direct band gap of the film is determined as $2.84 \mathrm{eV}$. Such high values of band gap width can be attributed to the quantum confinement effect, due to the small grain size in the nanocrystalline $\mathrm{PbS}$ thin films. The obtained band gap width is consistent with the reported values $[15,16]$.

The optical constants such as, the refractive index $(n)$ and extinction coefficient $(k)$ are calculated from $T$ and $R$ spectra of the film. The complex refractive index for any solid material can be expressed as

$$
n^{*}(\lambda)=n(\lambda)+\mathrm{i} k(\lambda) .
$$

The refractive index and extinction coefficient are calculated using the following equations:

$$
\begin{aligned}
& k=\frac{\alpha \lambda}{4 \pi}, \\
& n=\frac{1+R}{1-R}+\sqrt{\frac{4 R}{(1-R)^{2}}-k^{2}} .
\end{aligned}
$$

The spectral curves of $n$ and $k$ are shown in Fig. 4a. It is seen from the figure that the both $n$ and $k$ values are 2.52 and 0.15 , respectively at wavelength of $\lambda=550 \mathrm{~nm}$. Seghaier et al. [17] reported refractive index value $n=2.5$ for the $\mathrm{PbS}$ thin films. The obtained extinction coefficient is also higher than the other work [18].
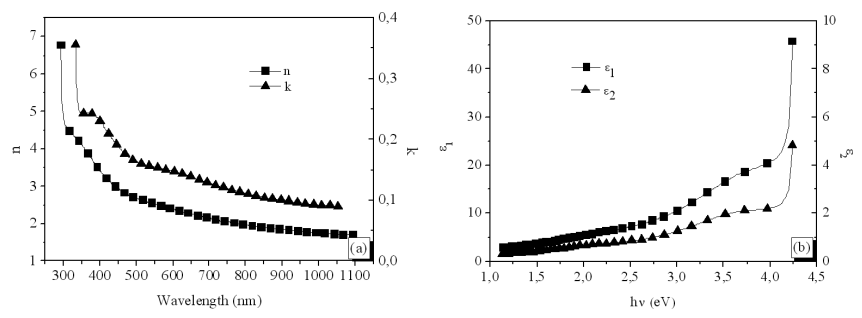

Fig. 4. (a) The plot of refractive index and extinction coefficient as a function of wavelength and (b) the dependence of real and imaginary parts of the dielectric constant on photon energy for the nanocrystalline $\mathrm{PbS}$ thin film.

It is well known that polarizability of any solid is proportional to its dielectric constant. The real $\left(\varepsilon_{1}\right)$ and imaginary $\left(\varepsilon_{2}\right)$ parts of dielectric constant are calculated using the following equations:

$$
\begin{aligned}
& \varepsilon_{1}=n^{2}-k^{2}, \\
& \varepsilon_{2}=2 n k .
\end{aligned}
$$

The real and imaginary parts of the dielectric constant are calculated by using $n$ and $k$ values from Eqs. (7) and (8). The real and imaginary parts of the dielectric constant are shown in Fig. 4b. The variation of the real part follows the same pattern as the imaginary part. As expected, the values of real part are higher than that of values of the imaginary part. The real and imaginary parts of the dielectric constant increase with increase of photon energy. The real and imaginary parts of the dielectric constant at $\lambda=550 \mathrm{~nm}$ are found as 6.35 and 0.77 , respectively. These values are consistent with reported data $[14,18]$ involving $\mathrm{PbS}$ films grown by $\mathrm{CBD}$.

The electrical constants such as electrical resistivity $(\rho)$ and conductivity $(\sigma)$, as well as carrier mobility $(\mu)$ and concentration $(N)$ of the $\mathrm{PbS}$ thin films are obtained from the Hall measurements. $\mathrm{PbS}$ thin films show electrical resistivity and conductivity of $3.722 \Omega \mathrm{m}$ and $0.268 \Omega^{-1} \mathrm{~m}^{-1}$, respectively. The measured electrical conductivity value lies in between $\sigma=1.29-3.7$ $\times 10^{4} \Omega^{-1} \mathrm{~m}^{-1}$ [13] and $\sigma=10^{-3}-10^{-4} \Omega^{-1} \mathrm{~m}^{-1}$ [19]. Moreover, the carrier mobility and concentration of the films are found as $8.486 \times 10^{-1} \mathrm{~m}^{2} \mathrm{~V}^{-1} \mathrm{~s}^{-1}$ and $1.976^{18} \mathrm{~m}^{-3}$, respectively. The mobility of the films is also higher than the previous data $[10,20]$.

\section{Conclusions}

Nanocrystalline PbS thin films are produced by the CBD method on glass substrates at room temperature for $2 \mathrm{~h}$. XRD results show that the obtained films have cubic rock salt phase of $\mathrm{PbS}$. The obtained films exhibit a preferential orientation along (111) plane. AFM images show that $\mathrm{PbS}$ thin films have nanostructures with the average grain size of $62 \mathrm{~nm}$ and thickness about $100 \mathrm{~nm}$. The band gap width of the films has been found as $2.84 \mathrm{eV}$ and this large optical band gap width in the films is attributed to the quantum confinement effect. The electrical resistivity, conductivity, carrier mobility and carrier concentration of the $\mathrm{PbS}$ films are found to be $3.722 \Omega \mathrm{m}, 0.268 \Omega^{-1} \mathrm{~m}^{-1}, 8.486 \times 10^{-1} \mathrm{~m}^{2} \mathrm{~V}^{-1} \mathrm{~s}^{-1}$ and $1.976 \times 10^{18} \mathrm{~m}^{-3}$, respectively.

From the structural, optical and electrical characterization, it can be inferred that $\mathrm{PbS}$ thin films with nanostructures offer opportunities for technological applications in optoelectronic devices.

\section{Acknowledgments}

This work has been partially supported by The Management Unit of Scientific Research Projects of Mehmet Akif Ersoy University under Project no. 0201-NAP-13.

\section{References}

[1] T. Duan, W. Lou, X. Wang, Q. Xue, Coll. Surf. A 310, 86 (2007).

[2] F.W. Wise, Acc. Chem. Res. 33, 773 (2000).

[3] A. Carrillo-Castillo, A. Salas-Villasenor, I. Mejia, S. Aguirre-Tostado, B.E. Gnade, M.A. QuevedoLópez, Thin Solid Films 520, 3107 (2012). 
[4] A.G.U. Perera, P.V.V. Jayaweera, G. Ariyawansa, S.G. Matsik, K. Tennakone, M. Buchanan, H.C. Liu, X.H. Su, P. Bhattacharya, Microelectron. J. 40, 507 (2009).

[5] J. Li, Y. Tang, J. Yang, Z. Yang, Y. Zhang, X. Hu, Sens. Actuat. B 190, 549 (2014).

[6] H.A. Mohamed, Sol. Energy 108, 360 (2014).

[7] C.Y. Wang, Y. Zhou, Y.R. Zhu, H.J. Liu, Z.Y. Chen, Mater. Res. Bull. 35, 1463 (2000).

[8] K.C. Preetha, K.V. Murali, A.J. Ragina, K. Deepa, T.L. Remadevi, Curr. Appl. Phys. 12, 53 (2008).

[9] F. Göde, E. Güneri, F.M. Emen, V.E. Kafadar, S. Ünlü, J. Lumin. 147, 41 (2014).

[10] H. Moreno-García, M.T.S. Nair, P.K. Nair, Thin Solid Films 519, 2287 (2011).

[11] S. Kaci, A. Keffous, M. Trari, O. Fellahi, H. Menari, A. Manseri, L. Guerbous, J. Lumin. 130, 1849 (2010).

[12] A. Stavrinadis, S. Xu, J.H. Warner, J.L. Hutchison, J.M. Smith, A.A.R. Watt, Nanotechnology 20 , 445608 (2009).
[13] R. Kumar, R. Das, M. Gupta, V. Ganesan, Superlatt. Microstruct. 75, 601 (2014).

[14] M.M. Abbas, A.Ab-M. Shehab, N.-A. Hassan, A.-K. al-Samuraee, Thin Solid Films 519, 4917 (2011).

[15] S. Kaci, A. Keffous, L. Guerbous, M. Trari, Thin Solid Films 520, 79 (2011).

[16] S. Kaci, A. Keffous, M. Trari, H. Menari, A. Manseri, J. Alloys Comp. 496, 628 (2010).

[17] S. Seghaier, N. Kamoun, R. Brini, A.B. Amara, Mater. Chem. Phys. 97, 71 (2006).

[18] M.M. Abbas, A.Ab-M. Shehab, A.-K. Al-Samuraee, N.-A. Hassan, En. Proced. 6, 241 (2011).

[19] K.M. Gadave, S.A. Jodgudri, C.D. Lokhande, Thin Solid Films 245, 7 (1994).

[20] I.E. Morales-Fernández, M.I. Medina-Montes, L.A. González, B. Gnade, M.A. Quevedo-López, R. Ramírez-Bon, Thin Solid Films 519, 512 (2010). 